

\title{
Políticas Públicas de Gênero no Contexto Escolar: Percepções de Orientadoras Educacionais
}

\author{
Políticas Públicas de Género en el Contexto Escolar: Percepciones de \\ Orientadoras Educacionales
}

\section{Public Policies of Gender in the School Context: Education Guidance Counselors' Perceptions}

\begin{abstract}
Resumo
O objetivo deste artigo é refletir sobre as políticas públicas de gênero no contexto escolar. $\mathrm{O}$ referencial teórico abarca autoras do campo de educação, gênero e políticas públicas. É uma investigação de caráter documental e pesquisa de campo com quatro orientadoras educacionais da rede municipal de ensino. Os dados foram interpretados de acordo com a análise de conteúdo qualitativo. $\mathrm{O}$ foco da análise reside nas contribuições das políticas públicas e as percepções de orientadoras educacionais acerca da implementação dessas políticas na prática escolar. Constatou-se que, embora haja conhecimento dessas políticas, existe uma ruptura entre o saber e o fazer pedagógico.
\end{abstract}

Palavras-Chave: Políticas Públicas; Gênero; Orientadoras Educacionais; Pedagogia da Equidade.

\section{Resumen}

El objetivo de este artículo es reflexionar sobre las políticas públicas de género en el contexto escolar. La referencia teórica abarca autoras del campo de la educación, género y políticas públicas. Es una investigación de carácter documental y pesquisa en terreno con cuatro orientadoras educacionales de la red municipal de enseñanza. Los datos fueron interpretados de acuerdo con el análisis de contenido cualitativo. El foco de análisis en las construcciones de las políticas públicas y las percepciones de orientadora educacionales acerca de la implementación de esas políticas en la práctica escolar. Se constató que, a pesar que exista conocimiento de esas políticas, existe una ruptura entre el saber y el hacer pedagógico.

Palabras-Clave: Políticas Públicas; Género; Orientadoras Educacionales; Pedagogía de la Equidad.

\begin{abstract}
The purpose of this article is to reflect on public policies of gender in the school context. The theoretical background includes authors from the fields of education, gender and public policies. It is a documental investigation and field research with four educational counselors from the municipal teaching network. Data were interpreted using the qualitative content analysis. The focus of the analysis lies on the contributions of public policies and the educational counselors' perceptions about the implementation of these policies in the school practice. It was found that, although there is knowledge of these policies, there is a gap between knowledge and pedagogical doing.
\end{abstract}

Keywords: Public Policies; Gender; Educational Counselor; Equity Pedagogy.

Lúcia Aulete Búrigo de Sousa, Mareli Eliane Graupe, Geraldo Augusto Locks, 


\section{Introdução}

Este artigo analisa percepções das orientadoras educacionais do Ensino Fundamental I no que se refere às políticas públicas de gênero no contexto escolar. A temática de educação e gênero é um debate contemporâneo e tem sido constantemente objeto de discussão em diferentes campos da sociedade brasileira.

A década de 1990 caracterizou-se como um período, no qual foram sancionadas leis e diretrizes que envolvem a temática de gênero e educação, tornando a escola um espaço privilegiado para desencadear discussões sobre perspectivas plurais neste campo, tendo em vista mudanças nas concepções teóricas e práticas pedagógicas que proporcionem a equidade de gênero.

A concepção epistemológica de análise neste texto é a perspectiva pósestruturalista $^{1}$, constituindo uma pesquisa documental, bibliográfica e empírica. Foram consultados documentos de quatro escolas de Ensino Fundamental I de uma rede municipal no Estado de SC, respectivamente, o Plano Municipal de Educação, Projeto Político Pedagógico e o Plano Anual de cada uma dessas unidades escolares.

É relevante este campo investigativo - políticas públicas de gênero -especialmente porque este tem sido motivo de debates polêmicos no âmbito do Congresso Nacional e de alguns segmentos da sociedade, gerando retrocessos nas políticas públicas já conquistadas. Forças conservadoras, sobretudo do campo religioso fundamentalista, vem se opondo à inserção da temática gênero e diversidade sexual na escola.

Mais recentemente, a mídia nacional passou a veicular matérias sobre o Programa Escola sem Partido, cujo objetivo é restringir a função do professor educador a um repassador de informações. Este Programa propõe a aprovação de leis em âmbito nacional, estadual e municipal que proíbem (às)aos professoras(es) serem reflexivos e críticos nos seus processos de ensino e aprendizagem. Segundo a Presidente da Associação Nacional de PósGraduação e Pesquisa em Educação, os defensores do Programa Escola sem Partido objetivam "[...] influenciar o legislativo para que sejam formulados projetos de lei de cerceamento da liberdade de ensinar e de livre expressão, sob o pretexto de combater pretensa doutrinação ideológica que estaria ocorrendo nas escolas brasileiras" (ANPED, 2016, s/p).

Além da ideologia da Escola Sem Partido, que desde 2004 é difundida no Brasil, destaca-se o movimento Ideologia de Gênero.

Em meados de 2014, no período de aprovação do Plano Nacional de Educação, e dos Planos estaduais e municipais no ano de 2015, emergiram diversos movimentos, organizados por representantes de grupos

\footnotetext{
1 O pós-estruturalismo pode ser caracterizado como um modo de pensamento, um estilo de filosofar e uma forma de escrita, embora o termo não deva ser utilizado para dar qualquer ideia de homogeneidade, singularidade ou unidade. O termo "pós-estruturalismo" é, ele próprio, questionável. De forma mais geral, podemos dizer que o termo é um rótulo utilizado na comunidade acadêmica de língua inglesa para descrever uma resposta distintivamente filosófica ao estruturalismo que caracterizava os trabalhos de Claude Lévi-Strauss (antropologia), Louis Althusser (marxismo) e Jacques Lacan (psicanálise) e Roland Barthes (literatura) (PETERS, 2000, p. 28).
} 
fundamentalistas, sustentando a exclusão da categoria gênero nestes documentos. Esse discurso de ideologia de gênero embasado em argumentos religiosos buscou convencer as autoridades públicas e a sociedade em geral de que a inclusão das categorias de gênero e sexualidade nos planos educacionais representariam "uma ameaça à família e às crianças".

\section{Políticas Públicas de Gênero}

É possível observar ao longo da história da educação brasileira que, principalmente temáticas relacionadas às questões de gênero são silenciadas ou, quando aparecem, têm sido relegadas a segundo plano. Isso deve-se ao fato de que a sociedade brasileira historicamente desenvolveu-se sobre a matriz cultural do patriarcado. Como observa Manuel Castells:

O patriarcado caracteriza-se pela autoridade, imposta institucionalmente, do homem sobre a mulher e filhos no âmbito familiar. Para que essa autoridade possa ser exercida, é necessário que o patriarcalismo permeie toda a organização da sociedade, da produção e do consumo à política, à legislação e à cultura (2013, p. 169).

Neste contexto, não se pode ignorar a relevância das políticas públicas de gênero na educação. Elas permitem a problematização de preconceitos, estereótipos e estigmas existentes no meio social escolar e não escolar.

As políticas públicas são importantes para a construção de conhecimentos sobre desigualdades entre homens e mulheres e na contribuição de ações governamentais na emancipação de sujeitos e segmentos sociais discriminados e excluídos dos direitos de cidadania. Neste sentido, Maria Paula Bucci considera "[...] política pública como um conjunto de ações ou normas de iniciativas governamentais, visando à concretização de direitos" (2002, p. 94). Diante disso, consideramos a política pública como mecanismo que deve buscar a efetivação de direitos e reduzir as desigualdades sociais, ou seja, ajudar na construção de relações igualitárias para todas(os).

Fúlvia Rosemberg (2001) ressalta a importância das políticas públicas educacionais na perspectiva da redução das desigualdades de gênero. A autora identifica que:

A produção de conhecimento sobre o atual desenvolvimento de políticas públicas de educação pela perspectiva de redução da desigualdade de gênero no sistema público de ensino brasileiro é ainda escassa e segue a tendência geral das pesquisas de gênero na educação, caracterizadas pela precária divulgação (ROSEMBERG, 2001, p. 16).

A inclusão de gênero na escola está associada à possibilidade de redução das desigualdades de gênero, do combate ao machismo, sexismo, racismo e homofobia. Para que isso ocorra, é essencial o investimento em pesquisas e na 
formação inicial e continuada de profissionais da educação em todos os níveis e modalidades de ensino.

Para Débora Jucely Carvalho (2011), os diferentes movimentos e organizações feministas no Brasil têm oferecido aportes significativos na afirmação da cidadania e conquista de igualdade de direitos das pessoas.

As lutas das mulheres brasileiras nos últimos anos, sua participação em diferentes movimentos feministas, tem afirmado sua cidadania, sendo uma luta pelo reconhecimento como sujeitos sociais, possuidoras de direitos (CARVALHO, 2011, p. 151).

De fato, é por meio dos movimentos sociais que as mulheres conquistam direitos e superam desigualdades sociais e políticas produzidas historicamente nas diferenças de sexo, gênero, raça/etnia e valores de classe.

Rosemberg (2001) chama a atenção para o quanto precisamos conhecer as políticas públicas educacionais para então diminuir as desigualdades de gênero. A luta pela igualdade pressupõe a premência de conquista e autarquia das mulheres para desenvolverem o poder de determinação e autonomia sobre o próprio corpo e vida.

Para a autora, as políticas públicas de gênero comprometem a estrutura de poder e fomentam o empoderamento das mulheres. Mudanças na ordem legislativa podem facilitar a igualdade de homens e mulheres, ou seja, para se conquistar a igualdade em todas as esferas, há necessidade de se apelar à equidade.

Por equidade de gênero compreendemos uma melhor aplicação da igualdade de gênero, incluindo as variáveis de classe, etnia, geração, religião, etc. Nesta perspectiva da equidade buscamos contemplar os critérios de justiça, de equivalência, de direito à igualdade para pessoas que se encontram em situações desiguais.

Neste contexto, entendemos a importância da escola em fomentar o reconhecimento das diferenças e de promover ações pedagógicas equitativas, considerando as diferentes necessidades das(os) estudantes.

A Lei de Diretrizes e Bases da Educação Nacional, número 9.394, de 1996, no Artigo $n^{\circ} 3$, refere que o ensino deve ser oferecido na base da "I - igualdade de condições para o acesso e permanência na escola; II - liberdade de aprender, ensinar, pesquisar e divulgar a cultura, o pensamento, a arte e o saber; [...] IV respeito à liberdade e apreço à tolerância [...]" (BRASIL, 1996).

A discussão de gênero é contemplada nos Parâmetros Curriculares Nacionais, no livro dos temas transversais "Orientação Sexual", e justifica-se mediante a necessidade da discussão e reflexão sobre os estereótipos, os papéis sociais atribuídos para meninas, meninos, homossexuais e heterossexuais no contexto escolar. $\mathrm{O}$ conceito de gênero é definido nos PCNs como:

O conjunto das representações sociais e culturais construídas a partir da diferença biológica dos sexos. Enquanto o sexo diz respeito ao atributo anatômico, no conceito de gênero toma-se o desenvolvimento das noções de masculino e feminino, como construção social. O uso 
desse conceito permite abandonar a explicação da natureza como a responsável pela grande diferença existente entre os comportamentos e lugares ocupados por homens e mulheres na sociedade. Essa diferença historicamente tem privilegiado os homens, na medida em que a sociedade não tem oferecido as mesmas oportunidades de inserção social e exercício de cidadania a homens e mulheres. [...] reivindica-se a inclusão da categoria gênero, assim como etnia, na análise dos fenômenos sociais, com o objetivo de retirar da invisibilidade as diferenças existentes entre os seres humanos que, por vezes, encobrem discriminações (BRASIL, 1997, p. 98 - 99).

A pretensão dos PCNs é que a perspectiva de gênero seja abordada nas escolas, de forma que valorize os direitos iguais para as meninas e os meninos, desvinculando os tabus e os preconceitos. Enfim, o trabalho sobre gênero tem como propósito combater relações autoritárias, questionar a rigidez dos padrões de conduta estabelecida para homens e mulheres e apontar para sua transformação.

Ainda nesta perspectiva de identificar políticas públicas que embasam a discussão sobre gênero na escola, destaca-se que, no ano de 2009, o Ministério da Educação lançou o 'Projeto Gênero, Diversidade e Educação' (GDE), com a finalidade de proporcionar formação continuada aos profissionais da educação básica da rede pública de ensino, com ênfase na temática de gênero, sexualidade, orientação sexual e relações étnico-raciais (BARRETO, ARAÚJO, PEREIRA, 2009).

Aproximadamente dezesseis anos após a publicação dos PCNs, presenciamos um retrocesso no que se refere às políticas públicas de gênero, quando o Plano Nacional de Educação 2014-2024, aprovado pela Lei 13.005, de 25 de julho de 2014, modifica a redação do Projeto de Lei 8.035/10, previsto para o decênio 2011-2020. No referido projeto, destacava-se a seguinte redação:

O projeto já havia sido apreciado pela Câmara e enviado ao Senado contendo duas passagens que empregavam a terminologia própria da ideologia de gênero. A primeira era o inciso III do artigo $2^{\circ}$ : Art. $2^{\circ}$ São diretrizes do PNE: [...] III - superação das desigualdades educacionais, com ênfase na promoção da igualdade racial, regional, de gênero e de orientação sexual. A segunda era a Estratégia 3.12 da Meta 3: 3.12) implementar políticas de prevenção à evasão motivada por preconceito e discriminação racial, por orientação sexual ou identidade de gênero, criando rede de proteção contra formas associadas de exclusão. O Senado Federal, porém, em dezembro de 2013, aprovou um substitutivo (PLC 103/2012) que eliminou toda essa linguagem ideológica. $\mathrm{O}$ inciso III do artigo $2^{\circ}$ ficou assim: Art. $2^{\circ}$ São diretrizes do PNE: [...] III - superação das desigualdades educacionais, com ênfase na promoção da cidadania e na erradicação de todas as formas de discriminação. A Estratégia 3.12 da Meta 3 foi 
renumerada para 3.13 e recebeu a seguinte redação: 3.13) implementar políticas de prevenção à evasão motivada por preconceito ou quaisquer formas de discriminação, criando rede de proteção contra formas associadas de exclusão. De volta à Câmara, o projeto foi analisado por uma Comissão Especial, tendo como relator o deputado Angelo Vanhoni (PT/PR). Fiel ao seu Partido, Vanhoni emitiu um parecer com complementação de voto pela reincorporação da ideologia de gênero no PNE. Decidiu assim, 1) rejeitar o inciso III do art. $2^{\circ}$ do Substitutivo do Senado Federal e retornar em seu lugar o inciso III do art. $2^{\circ}$ do texto da Câmara dos Deputados; [...] 34) rejeitar, na estratégia 3.13 do Substitutivo do SF, a expressão "implementar políticas de prevenção à evasão motivada por preconceito", restabelecendo em seu lugar a expressão "implementar políticas de prevenção à evasão motivada por preconceito e discriminação racial, por orientação sexual ou identidade de gênero", da estratégia 3.12 do texto da Câmara de Deputados (BRASIL, 2014, s./p. ).

Conforme Ofício $n^{\circ}$ 2.816/2013-SF da Câmera de Deputados, documento importante para entendermos os movimentos realizados antes da votação oficial do Plano Nacional de Educação, o texto do PNE 2014-2024 surpreendeu muitos(as) educadores(as) com as mudanças efetuadas a respeito da política de gênero. Essa questão aparece somente uma vez no atual Plano, na meta oito, quando aborda a desigualdade de gênero ${ }^{2}$ entre a população negra. Constata-se, ainda, que as mudanças relacionadas às políticas de gênero ficaram reduzidas e ineficazes.

De acordo com o Plano Estadual de Educação (2015-2024) de Santa Catarina, a escola, em seu Projeto Político Pedagógico (PPP), deve contemplar, por meio de eventos, encontros, reuniões participações de familiares e responsáveis, o acompanhamento de todas as atividades escolares de seus/suas filhos(as), havendo uma relação maior entre escola e família.

Cabe ressaltar que, no Plano Estadual de Educação, consta como política estadual de formação inicial e continuada a discussão de gênero na meta 15 , na sua estratégia 13, "Implantar programas de formação dos profissionais da educação, sobre gênero, identidade de gênero, sexualidades, orientação sexual, educação ambiental e educação especial, para a promoção e efetivação dos

2 Elevar a escolaridade média da população de 18 a 29 anos, de modo a alcançar no mínimo 12 anos de estudo no último ano, para as populações do campo, da região de menor escolaridade no país e dos $25 \%$ mais pobres, e igualar a escolaridade média entre negros e não negros declarados à Fundação Instituto Brasileiro de Geografia e Estatística (IBGE). [...] No que se refere à população negra entre 25 e 29 anos, 1,5\% não conta com nenhum nível de escolaridade, $84,1 \%$ estão fora da escola e apenas $5,7 \%$ possuem o ensino superior completo. Essas desigualdades também se refletem na participação e rendimento no mercado de trabalho. Considerando a desigualdade de gênero, a população negra apresenta as mais elevadas taxas de desocupação e de rendimento, ainda que disponham do mesmo nível de escolaridade. Segundo estudo do IPEA (2012), a taxa de desocupação do homem negro é de $6,7 \%$ e da mulher negra de $12,6 \%$, enquanto que do homem e mulher não negros é de $5,4 \%$ e $9,3 \%$, respectivamente (BRASIL, 2014, p. 31 - 32). 
direitos sociais" (SANTA CATARINA, 2015, p. 133).

Ainda no Plano Estadual de Santa Catarina, a meta 14, sobre os cursos de pós-graduação em nível de mestrado e de doutorado, enfatiza na estratégia 9 a importância da discussão de gênero:

Estimular estudos e pesquisas em direitos humanos e inclusão, sobre gênero, orientação sexual e identidade de gênero, diversidade religiosa, relações étnico-raciais, educação ambiental, tecnologia assistiva, pedagogia da alternância, quilombola, indígena, povos do campo, comunidades tradicionais, para pessoas, público da educação especial, e em situação de privação de liberdade. (SANTA CATARINA, 2015, p. 131), (Grifos nossos).

Observamos que o Plano Estadual de Educação contempla, em algumas metas e estratégias, a discussão de gênero, caracterizando uma política pública importante para a implementação dessa discussão no cotidiano escolar. No Plano Nacional de Educação, por sua vez, a temática de gênero e sexualidade foi suprimida.

Além do Plano Estadual de Educação de Santa Catarina, podemos citar a Proposta Curricular de Santa Catarina (2014), documento norteador do trabalho pedagógico no Estado.

Cabe aqui ressaltar que as diretrizes estabelecidas pela Secretaria Estadual de Educação na Proposta Curricular demonstram a preocupação no desenvolvimento, reconhecimento $\mathrm{da}(\mathrm{o})$ educanda(o) nas condições de um sujeito histórico, cidadã/cidadão pleno de direitos e deveres. Nesse sentido, esse documento enfatiza a relevância da discussão de gênero e sexualidade na formação de professoras(es) e na prática pedagógica.

Referente às temáticas de quem são os sujeitos da diversidade, gênero e orientação sexual, encontramos na Proposta Curricular, nas páginas 56 até 62, conceitos e orientações sobre a necessidade da discussão e implementação dessas temáticas na educação básica:

Portanto, uma Educação para as Relações de Gênero, no âmbito da Educação Básica, reconhece esta categoria identitária como importante na vida das pessoas (sejam elas crianças, jovens, adultos e idosos). Falar em gênero é perceber como, para homens e mulheres, para meninos e meninas, a cultura, a sociedade e o atual tempo histórico constroem diferentes formas de "ser masculino" ou "ser feminino" (masculinidades e feminilidades). O conceito "gênero" não é o mesmo que "sexo" (nossa biologia). O gênero rejeitará o determinismo biológico e concederá ênfase cultural na distinção entre os sexos (SANTA CATARINA, 2014, p. 58).

O Estado de Santa Catarina possui um Plano Estadual de Educação e uma Proposta Curricular que abarcam as discussões sobre gênero, identidade de gênero e sexualidades, no entanto, essas duas importantes referências não são o 
suficiente para que as políticas públicas de gênero venham a ser contempladas nas esferas municipais, como por exemplo o município em que esta pesquisa foi realizada, não considerou a discussão de gênero e sexualidade no Plano Municipal de Educação.

O Plano Municipal de Lages (2014) não faz referência nas suas metas e estratégias sobre a educação de relações de gênero e diversidade sexual na escola. Consta apenas quatro vezes a palavra gênero associada aos dados de localização e população. É importante lembrar que a Proposta Curricular de Santa Catarina (2014) e o Plano Estadual de Educação (2015) deste referido Estado abordam com ênfase a discussão de gênero e diversidade sexual no campo educacional. As palavras orientação sexual, diversidade sexual, identidade de gênero, relações de gênero e homofobia não são consideradas no documento norteador da educação municipal em Lages. Na meta 4, estratégia 27, há uma abertura para a discussão de violências de forma genérica, mas não constando de maneira explícita as violências de gênero contra estudantes LGBT e violência doméstica, como podemos observar: "Desenvolver projetos específicos com ações voltadas ao combate dos diferentes tipos de violências nas escolas" (LAGES, 2014, p. 29).

Para se efetivar as exigências do Plano Estadual de Educação e as Diretrizes da Proposta Curricular, considera-se fundamental a articulação e a incorporação destas exigências e orientações nos Planos Municipais e nos Projetos Políticos Pedagógicos das Escolas.

Convém destacar que a garantia das conexões descritas acima pressupõe a formação inicial e continuada de gestoras (es) públicos que atuam com a política educacional, orientadoras (es) educacionais diretoras (es), professoras (es), englobando toda a comunidade educativa escolar.

Tematizar gênero e diversidade tanto na formação inicial quanto na formação continuada dos (as) professores (as) torna-se relevante para que esses sujeitos sejam promotores da cultura de respeito e efetivação de direitos, com base na equidade de gênero, étnico-racial, diversidade, justiça e igualdade para todos(as).

Estas políticas devem estar em consonância com um Projeto Político Pedagógico consistente e incorporado na prática pedagógica. O Planejamento Anual, em conformidade com as diretrizes gerais e com a organização escolar, também deve incluir em sua pauta a questão da diversidade de gênero. Trata-se de um caminho coletivo a ser trilhado para que a igualdade de gênero no espaço educacional seja efetivada.

Se o PPP é o espelho da sala de aula, da escola, ele não pode ser considerado apenas um documento no qual se relaciona regras, normas e sistemas avaliativos dos estudantes. Faz-se necessário que não se reconheça no PPP tão somente o cumprimento de exigências governamentais ou ainda que se torne um documento engessado e engavetado pelos profissionais que constituem o espaço educacional. Mais do que isso, o Projeto PolíticoPedagógico "[...] exige profunda reflexão sobre as finalidades da escola, assim como a explicação de seu papel social e a clara definição de caminhos, formas operacionais e ações a serem empreendidas por todos os envolvidos com o processo educativo" (VEIGA, RESENDE, 2003, p. 9).

A análise realizada sobre algumas políticas públicas que propiciam a 
discussão de gênero no contexto escolar (LDB 9394/96, os Parâmetros Curriculares Nacionais -1997), Plano Nacional de Educação - 2014 a 2024, Plano Estadual de Santa Catarina - 2015 a 2024 e Municipal - 2014 a 2024, Projeto Político -Pedagógico e Plano Anual) aponta que é importante a implementação/discussão das políticas públicas na formação de professoras(es) e nas práticas pedagógicas. No entanto, embora prevaleça a questão da institucionalização da temática por meio de políticas públicas, não se pode esquecer de que é na unidade escolar que a discussão de gênero será ou não colocada em prática.

\section{Políticas Públicas de Gênero: Percepções de Orientadoras Educacionais}

A coleta e análise de dados seguiu o proposto por Mayring e Flick e constitui-se como estudo qualitativo, com revisão de literatura, pesquisa documental e de campo. A partir do objetivo proposto, a pesquisa empírica foi desenvolvida sob o método de entrevista focalizada, por apresentar a possibilidade de um diálogo que facilita a interação entre duas ou mais pessoas, em uma troca de informações, e dá sentido à realidade que abrange os sujeitos (FLICK, 2009).

A entrevista foi realizada em quatro escolas municipais com suas respectivas orientadoras escolares. A escolha de orientador(a) teve por base o critério de mais de quatro anos de atuação na rede municipal de ensino. As escolas pesquisadas são identificadas por codinomes e as orientadoras participantes da pesquisa foram identificadas por Orientadora " $A$ "; Orientadora "B"; Orientadora "C" e Orientadora " $D$ ".

Quando interrogamos a orientadora D sobre a implementação da discussão de gênero e sexualidade na sua escola, ela mencionou:

A gente sempre procura tratar todo mundo com muita naturalidade, que tem que ser todos bem recebidos, que somos todos iguais e temos todos os mesmos direitos. Então essa foi uma das situações e nós temos alguns alunos, meninas e meninos, que já se decidiram sexualmente. Então a gente procura tratar com naturalidade. Quando a gente começa detectar, não aceitamos nenhum tipo de discriminação. Havendo algum tipo de discriminação, já vamos logo tentando apagar o foco de incêndio. Mas a gente sabe que isso ainda é muito pouco, ainda mais porque nós temos colegas que ainda não aceitam. Nós temos pais também que não aceitam. Isso é o início de uma caminhada na qual sabemos que vão ocorrer muitos problemas, muitos incidentes. E é uma luta que está aí e a gente vai ter que trabalhar (Orientadora “ $D$ ”).

Observamos que a temática de gênero e sexualidade é insipiente no contexto escolar, e que muitas profissionais da educação continuam com uma prática excludente, reprodutora de comportamentos e padrões heterossexistas, incluindo a prevalência de uma rejeição a este debate.

Segundo os PCNs, cabe à escola elaborar sua proposta de ensino sobre o tema diversidade sexual, a fim de disseminar outros valores que minimizem e 
aos poucos acabem com os preconceitos e as violências de gênero. No entanto, antes de colocar em prática essas ações, as(os) educadoras(es) precisam superar as próprias dificuldades em tratar sobre essa temática.

Enquanto professores(as), gestores(as) e demais profissionais envolvidos(as) no processo de ensino aprendizagem se abstiverem de discussões construtivas quando perceberem atitudes ou falas preconceituosas entre alunos(as) e familiares, a escola tenderá a manter o estereótipo e o preconceito.

A dificuldade dos(as) docentes em tratar sobre a questão da sexualidade foi identificada nas palavras da Orientadora "A" ao referir que:

Coloca o professor, eu não estou preparado para trabalhar educação sexual, eu vou buscar, mas esse buscar às vezes é um tempo que excede um ano. Você percebe que no outro ano, quando você vê que não se desencadeou, na verdade ele tem receio e medo, por mais que às vezes até busque formação do tema, mas ele ainda não tem segurança para isso, ai não passa. Se eu não estiver segura eu não vou passar para as crianças, então é uma coisa que vai ficando guardado, vai sendo armazenada ali e ele não consegue. Em outros procedimentos, em outras coisas a gente vê mudanças, a postura do professor muda na questão lá dos procedimentos, planejamento, intervenção, mas nessa questão de educação sexual é muito complicado. Eu acredito que é em função daquilo que veio de casa sabe? Porque aquilo que eu trago, por mais que eu passe por uma formação, que eu conviva com outras pessoas, que eu tenha alguma evolução, [...] aquilo que aconteceu lá na minha infância fica marcado para o resto da vida. Fica guardado lá e ai é difícil superar isso. Então, se eu não tenho segurança, eu não vou falar, eu vou passar batido, eu não vou me encorajar e me dispor (Orientadora “ $A$ ”).

A partir desse relato, é importante mencionar a realidade das escolas quanto à manutenção de modelos sociais. A fala da entrevistada revela que há receio e negação por parte dos(as) professores(as) em trabalhar temas relacionados à sexualidade. A própria insegurança da escola, representada pela orientadora escolar, contribui para que essa situação continue, quando deixa a cargo da(o) professor(a) o trabalho com as diferenças e não há cobranças quanto a essa retomada do tema no contexto escolar. A relação dos conteúdos sobre gênero, identidade de gênero e sexualidade ficam abertas nessas escolas, dependendo de cada docente o desenvolvimento, em sala de aula ou em espaços sociais, de práticas e comportamentos que promovam a igualdade entre os gêneros.

Outra questão importante a ser observada é uma espécie de jogo de empurra de responsabilidades - o(a) orientador(a) deixa para o(a) professor(a), o(a) professor(a) não faz porque não é cobrado(a). Quando isso acontece, há a desculpa de que não se consegue trabalhar a temática da sexualidade e de gênero e a orientação pedagógica se exime de sua principal função, que é a de orientar o processo pedagógico. E nisso pode incluir-se também a temática da sexualidade e das questões de gênero. 
Para superar um preconceito, é necessário que se trabalhe em conjunto, mas o receio e a insegurança quanto à discussão de gênero e sexualidade são frequentes no contexto escolar.

Adiante em sua conversa identificamos as seguintes colocações:

Acho que temos certo receio, mas eu tenho certa facilidade, fui criada em uma igreja evangélica tradicional, eu não tenho dificuldade com essa coisa de sexual, eu não tenho nenhum problema de trabalhar na escola a sexualidade. Temos professora lésbica, professor homossexual esse ano não, acho que por isso o receio, porque você sabe que geralmente quem é homossexual não se aceita, então é mais difícil de trabalhar esse tema, porque você tem que saber até que ponto esse professor se aceita, entendeu? (Orientadora " $C$ ").

A leitura e análise das respostas das entrevistadas nos colocam em alerta para uma situação bastante comum, a do discurso pró-sexualidade imerso em preconceito, principalmente ao jogar o problema para sujeitos homossexuais. São eles que não aceitam sua homossexualidade ou a sociedade que os exclui? A pergunta que fizemos (como a escola trabalha a temática de gênero $\mathrm{e}$ sexualidade) provocou a contradição, e isso representa a dificuldade que as pessoas têm em aceitar a diferença como "normal". O diferente é encarado como problema, com o qual as(os) educadoras(es) apresentam dificuldades para trabalhar com as diferenças. Conforme a orientadora "C", por exemplo, o grupo escolar procura estabelecer uma ordem e cumprir a mesma.

Outra orientadora educacional afirmou:

Temos que trabalhar relações de gênero, porque se eu não sei nem quem eu sou, como é que eu vou trabalhar esta questão com os outros? Eu primeiro tenho que trabalhar quem eu sou, porque se até nós fizermos um apanhado não sabemos quem a gente é exatamente. Mas claro que primeiro eu teria que estudar este tema, me aprofundar mais. Eu começaria trabalhando esta questão do eu enquanto ser, eu começaria por aí. Traria um psicólogo, até uma pessoa que saiba trabalhar este tema. Eu iniciaria um trabalho com os adolescentes para posteriormente, abordar com os professores. Os professores de ciências, e a gente sabe que há muitos anos vem se trabalhando isso, que não é por disciplina, porque nós temos que trabalhar um contexto, um todo (Orientadora “ $D$ ").

A orientadora " $D$ " entende essa necessidade e também as próprias dificuldades em assumir sua função de orientar os(as) professores(as) para a discussão da temática de gênero e sexualidade. Ela apresenta uma metodologia para iniciar o debate da temática de gênero e sexualidade: começaria com adolescentes e, posteriormente, discutiria com os profissionais da educação. Pontua que esta temática é geralmente discutida pelos professores do campo das ciências, indica a discussão por meio de palestrantes, o que ainda demonstra uma visão reducionista deste tema no campo da educação. Gênero e sexualidade são temas a serem abordados da educação infantil até a formação 
continuada de professores.

Tal como já assinalamos, a escola e os(as) professores(as) necessitam reconstruir significados sociais para dar conta de sua diversidade e de sua inserção em situações diferentes na vida escolar dos(as) alunos(as). A respeito das políticas de formação de professores(as) oferecida pela Secretaria de Educação Municipal de Lages, a Orientadora "C" faz revelações importantes para essa discussão:

Na formação este ano nós não trabalhamos nada a respeito de gênero e sexualidade, eu acho que a gente nunca trabalhou esse tema específico, e nunca ouvi uma solicitação dos professores. Que eu lembre não. Penso que como deveria não, dentro só da diversidade cultural, escola integral e vários outros temas, mas nós enquanto escola não, eu passo vídeos para os professores em nossas reuniões, mas assim ter textos e jogar o tema como discussão, não (Orientadora "C").

Também são reveladoras as palavras da Orientadora " $\mathrm{D}$ " a respeito dos processos formativos veiculados por meio de políticas públicas educacionais e do velamento em que são mantidas temáticas complexas, mas necessárias no cotidiano escolar: "[...] nas paradas pedagógicas ainda não abordamos, é um assunto difícil, é que estamos aguardando para trabalhar, e queremos trazer alguém, já que ganhamos esta oportunidade, provavelmente nós vamos procurar por vocês para isso". De outro ponto de vista a Orientadora "B" afirma:

Olha este ano não foi trabalhado esse tema, foi trocado bastante o professor por causa do concurso que foi feito, então temos vários professores novos. Estou trabalhando com estes novos agora também. Mais com os outros que já eram da escola e que a gente já tinha trabalhado sobre isso... $\dot{E}$ tudo muito normal. Acontece tudo normalmente e com os outros a gente está fazendo com que isso aconteça, aqui nada é um absurdo, é tudo normal (Orientadora "B”).

O que seria a normalidade expressa nessas palavras? Se o Estado se exime dessa discussão, se os depoimentos anteriores dessas mesmas orientadoras deixam transparecer sua resistência em discutir, orientar, refletir com os(as) professores(as) a temática de gênero e, mesmo, em aceitar a diferença, a diversidade, a homossexualidade na escola, como podemos pensar que "tudo é muito normal", natural? O caminho para a mudança de percepção é longo e precisa começar pelo próprio sujeito, mas isso é identificado no(a) outro(a). É o(a) outro(a) que precisa mudar, não Eu. E assim entendemos o porquê da perpetuação de comportamentos homofóbicos, da violência, da negação, da incompreensão e do preconceito.

Segundo Antonio Flavio Barbosa Moreira e Vera Maria Candau:

Os preconceitos e as discriminações estão fortemente radicados nas nossas mentalidades e no imaginário coletivo da nossa sociedade. 
Impregnam nosso dia a dia, nossos comportamentos, nossas atitudes e práticas sociais. Desintegrá-los exige um processo consciente, cuidadoso e sistemático de desnaturalização, sensibilização, reflexão e ação no plano pessoal e coletivo, que trabalhe os âmbitos cognitivo, afetivo, simbólico, cultural e político-social (2003. p. 100).

Essa constatação de Moreira e Candau confirma o que discutimos até aqui quanto à negação das discussões sobre gênero nas escolas. Trata-se de um processo cultural arraigado nas mentes, nas ações, nos comportamentos e na compreensão dos sujeitos que estão à frente do trabalho nas escolas. A escola, na sociedade ocidental, é compreendida como um dos principais ambientes formativos para a cidadania, mas quando se trata de assuntos tão importantes quanto as temáticas de gênero, todos(as), desde o discurso do Estado veiculado em legislações, programas, formações, até os(as) orientadores(as) escolares e os(as) professores(as), associados à família e aos estereótipos marcados socialmente, se eximem de seu compromisso com a mudança para a construção de uma sociedade menos preconceituosa, mais igual e justa.

Entendemos que a escola se constitui como uma das instituições mais importantes da formação do(a) cidadão(ã). Educar alunos(as) para respeitar as diferenças, sejam elas culturais, de gênero ou raciais, contribui para a reafirmação da igualdade de direitos, oportunidades e acesso aos bens sociais e à diminuição da homofobia na escola, da violência gerada pelo preconceito.

Nesse processo, um dos aspectos importantes a ser considerado na prática pedagógica cotidiana é o que está inscrito nos Planos Anuais e PPP das escolas. Se nesses documentos se exime de propor discussões relativas às temáticas de gênero ou, se por ventura essa temática seja contemplada, gestores(as), orientadores(as), educadores(as) não assumirem suas funções e responsabilidades para que isso seja de fato colocado em prática nas salas de aula, o processo continuará falho e a mudança será postergada para a tentativa das futuras gerações em resolver essas questões.

\section{Considerações Finais}

As análises realizadas referentes às políticas públicas de gênero e às falas das orientadoras educacionais nos incitam a refletir sobre os limites e potencialidades de uma política pública. Entende-se que existem lacunas de conhecimentos por parte das próprias professoras sobre as políticas que possibilitam a inserção da discussão de gênero no contexto escolar. Por outro lado, também, constata-se a necessidade de um engajamento das orientadoras educacionais com a temática de gênero. Essas profissionais da educação abordam a discussão de gênero e sexualidade no contexto escolar, mas ao mesmo tempo buscam justificar o porquê desses temas não serem pautados nas práticas pedagógicas.

As escolas ainda possuem dificuldades consideráveis na realização/efetivação de um trabalho relacionado à questão de gênero, pois a incerteza dos(as) professores(as) na hora de agir persiste, configurada por uma postura hierárquica e autoritária a partir da qual gênero/sexo são dicotomizados, e sexualidade é entendida como um tema tabu e de 
responsabilidade da própria família.

Constatou-se com as reflexões sobre as políticas públicas de gênero e suas implementações no campo da educação a partir da década de 1990, juntamente com a breve análise das percepções das orientadoras quanto à implantação das políticas públicas de gênero na rede municipal, que essa temática aparece de forma indireta, quase velada, no cotidiano escolar. Identificou-se que o conceito de gênero não é praticamente discutido e nem trabalhado no contexto escolar. Embora haja conhecimento dessas políticas, existe ainda uma ruptura entre o saber e o fazer pedagógico.

Neste contexto, objetiva-se que a temática de gênero e outras categorias relacionadas (classe, sexualidade, etnia/raça, religião, orientação sexual, etc.) sejam trabalhadas na perspectiva da equidade de gênero, ou seja, uma educação que reconheça as diferenças entre os gêneros, mas não faça desta diferença uma barreira para o desenvolvimento individual de cada ser humano.

Sabendo que a escola é considerada um lugar oportuno para o trabalho com o conhecimento, entende-se que ela deve oportunizar aos(às) alunos(as) o pensar, o refletir e o transformar a realidade da qual fazem parte. Desse modo, a escola poderá possibilitar a desconstrução e reconstrução de conceitos, padrões, competências, para que seja possível a formação de alunos(as) responsáveis, participativos(as), críticos(as), livres de estereótipos, preconceitos e colaboradores(as) na construção de uma sociedade igualitária para todos(as).

Em suma, podemos dizer que há políticas públicas no campo educacional brasileiro que possibilitam a discussão de gênero na escola, no entanto, constata-se um distanciamento entre as leis, diretrizes e os planos e a implementação da discussão de gênero nas práticas pedagógicas. Consideramos que é urgente a construção e publicação de 'Diretrizes Nacionais de Gênero e Sexualidades na Escola', especialmente neste momento histórico, em que as ideologias do Programa da Escola sem Partido são disseminadas por meio de projetos de lei municipal, estadual e nacional.

\section{Referências}

ANPED. Escola Sem Partido. 2016. Disponível em: $<$ http://www.anped.org.br/news/carta-da-presidente-da-anped-aos-deputadosfederais-sobre-o-seminario-da-bncc $>$. Acesso em 5 de Julho de 2018.

BARRETO, Andreia; ARAÚJO, Leila; PEREIRA, Maria Elizabete. Gênero e diversidade na escola: formação de professoras/es em gênero, orientação sexual e relações étnico-raciais. Livro de conteúdo. Rio de Janeiro: CEPESC; Brasília: SPM, 2009.

BRASIL. Câmara de Deputados. Projeto de lei n. 8.035. Disponível em: $<$ http://www2.camara.leg.br/atividade-legislativa/comissoes/comissoestemporarias/especiais/54a-legislatura/pl-8035-10-plano-nacional-deeducacao/documentos/outros-documentos/avulso-pl-8035-10-c >. Acesso em 25 de Julho de 2018. 
BRASIL. Lei no 9.394, de 20 de dezembro de 1996. Lei de Diretrizes e Bases da Educação Nacional. Presidência da República. Casa Civil. Brasília, 1996. Disponível em: < http://www.planalto.gov.br/ccivil_03/leis/19394.htm>. Acesso em 25 de Julho de 2018.

BRASIL. Ministério da Educação. Plano Nacional de Educação de 20112020.

$<$ http://portal.mec.gov.br/index.php?option=com_content\&id= $16478 \&$ Itemid $=1107>$. Acesso em 25 de Julho de 2018.

BRASIL. Planejando a Próxima Década. Conhecendo as 20 metas do Plano Nacional de Educação/2014. Disponível em: <http://pne.mec.gov.br/pdf/pne conhecendo_20_metas.pdf $>$. Acesso em 12 de Julho de 2018.

BRASIL. Secretaria de Educação Fundamental. Parâmetros Curriculares Nacionais: Introdução aos Parâmetros Curriculares Nacionais. Brasília: MEC/SEF, 1997.

BRASIL. Secretaria de Educação Fundamental: Parâmetros Curriculares Nacionais: terceiro e quarto ciclos: apresentação dos temas transversais / Secretaria de Educação Fundamental. Brasília: MEC/SEF, 1998.

BUCCI, Maria Paula Dallari. Direito administrativo e políticas públicas. Revista de informação Legislativa, v. 34, n. 133, p. 89 - 98, 1997.

CARVALHO, Débora Jucely. A conquista da cidadania feminina. Saber Acadêmico, Revista Multidisciplinar da UNIESP, São Paulo, n. 11, p. 143 153, 2011.

CASTELLS, Manuel. O poder da Identidade. Tradução de Klauss Brandini Geshardin. São Paulo: Paz e Terra, 2013.

FLICK, Uwe. Introdução à pesquisa qualitativa. Tradução de Joice Elias Costa. 3. ed. Porto Alegre: Artmed, 2009.

LAGES. Lei n. 4114, de 23 de junho de 2015. Aprova o Plano Municipal de Educação e dá outras providências. Disponível em: $<$ https://leismunicipais.com.br/plano-municipal-de-educacao-lages-sc $>$. Acesso em 30 de Julho de 2018.

MOREIRA, Antonio Flavio Barbosa; CANDAU, Vera Maria. Educação escolar e cultura(s): construindo caminhos. Revista Brasileira de Educação, n. 23 , p. $156-168,2003$.

PETERS, Michael. Pós-estruturalismo e filosofia da diferença: uma introdução. Belo Horizonte: Autêntica, 2000.

ROSEMBERG, Fúlvia. Caminhos cruzados: educação e gênero na produção 
acadêmica. Educação e Pesquisa, v. 27, n. 1, p. 47 - 68, 2001.

\section{SANTA CATARINA. Plano Estadual de Educação de Santa Catarina. Florianópolis: $\quad$ SEEI, 2004. Disponível em:} http://www.sed.sc.gov.br/index.php/documentos/plano-estadual-de-educacaosc-452. Acesso em 30 de Julho de 2018.

SANTA CATARINA. Plano Estadual de Educação de Santa Catarina. Florianópolis: SEEI, 2015. Disponível em: $<$ http://www.sed.sc.gov.br/index.php/documentos/plano-estadual-de-educacaosc-452>. Acesso em 5 de Julho de 2018.

SANTA CATARINA. Proposta Curricular de Santa Catarina: estudos temáticos. Secretaria de Estado da Educação, Ciência e Tecnologia. Florianópolis: IOESC. 2014. Disponível em: $<$ http://www.propostacurricular.sed.sc.gov.br/site/Proposta_Curricular_final.pd f. Acesso em 5 de Julho de 2018.

VEIGA, Ilma Passos Alencastro; RESENDE, Lucia Maria Gonçalves de. (Orgs.). Escola: espaço do projeto político-pedagógico. 7. ed. São Paulo: Papirus, 2003. 